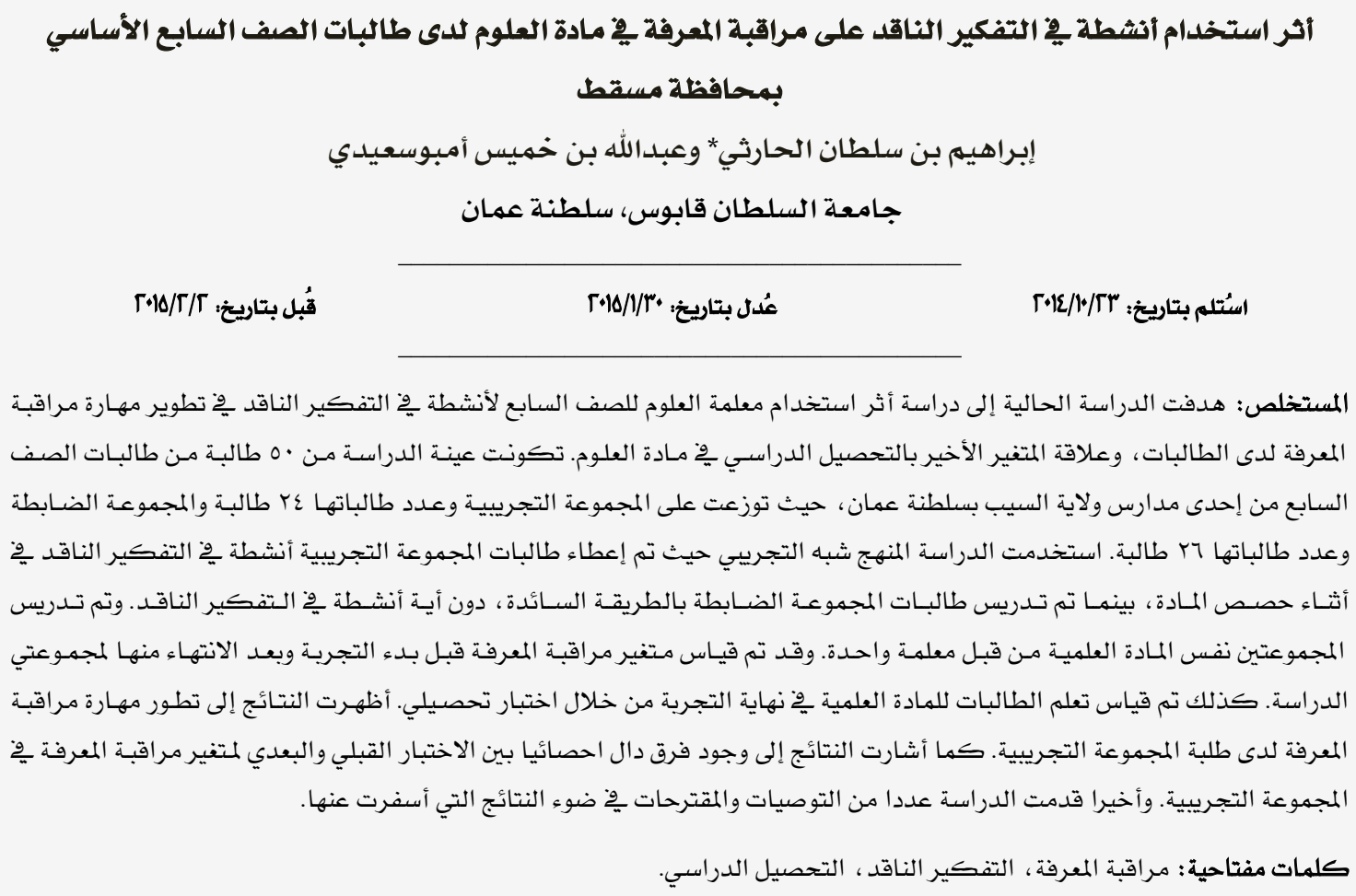

\title{
The Effect of Using Critical Thinking Activities on Knowledge Monitoring in Science of Seventh Graders in the Sultanate of Oman
}

Ibrahim S. Al-Harthy * \& Abdullah K. Ambusaidi Sultan Qaboos University, Sultanate of Oman

\begin{abstract}
The aim of the current study was to investigate the effects of using critical thinking activities in the classroom to enhance and develop students' knowledge monitoring and whether knowledge monitoring predicts students' academic achievement in Science. Fifty females were randomly selected from the seventh grade at one of Al-Saeeb province schools in Muscat governorate. Subjects were assigned to an experimental group $(n=24)$ and to a control group $(n=26)$. Both groups were taught same materials by the same teacher. The critical thinking activities were manipulated into the experimental group, whereas the control group received no critical thinking activities. Pre and post tests of knowledge monitoring were obtained. Subjects took an academic test at the end of the experiment. The results demonstrated that knowledge monitoring in experimental group significantly improved. Significant differences were found between pre and post knowledge monitoring in the experimental group. Recommendations and suggestions are discussed.
\end{abstract}

Keywords: Knowledge monitoring, critical thinking, academic achievement.

*ibrahimh@squ.edu.om 
ببذل وقت كاف واستخدام طرق جيدة للإجابة على الههمـة.

ولهم يقتصر ظهور ما وراء المعر فة على فلافل ） (Flavell, 1979) باندورا (Bandura, 1977) إلى متغير التنظيم

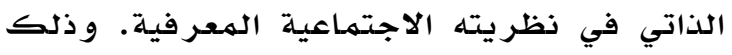
لان متغير التتظيم الذاتي يحتاج إلى عمليات

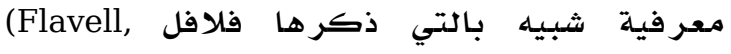

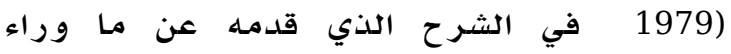

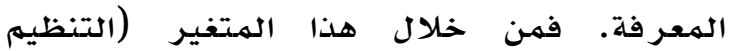

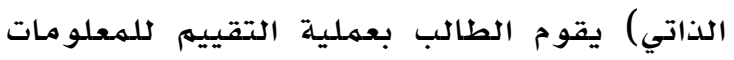

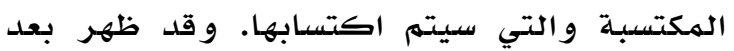
ذلك العديد من الأطر التي حأولت تقديهم إطار

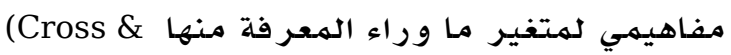
Paris, 1988; Pintrich, Walters and Baxter, 2000; Schraw \& Dennison, 1994; Tobias \& Everson, 2002)

وعلى الرغم من تعدد الأطر التي تنأولت متغير

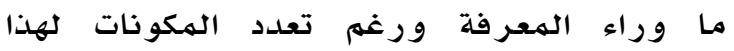
المتغير إلا إن جميعها يتفق على أن ماء ورواء ورهماء المعرفة هو عبارة عن استراتيجيات و مهارات في إتهي

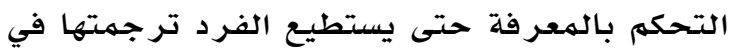

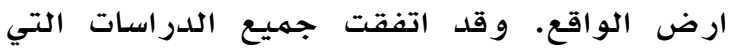

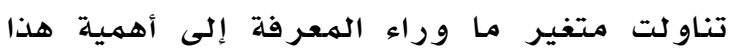
المتغير و علاقته الايجابية بالتحصيل والانجاز

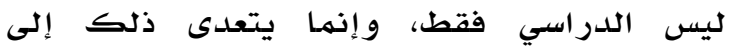
مواضيع وواجبات أخرى قد يواجهها الفرد على إلى إلى

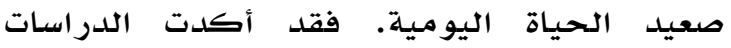
(Al-Harthy \& Was, 2013; Swanson, السابقة اهيديل

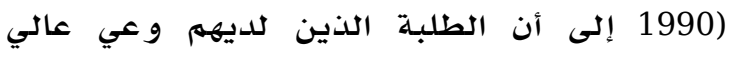
بمكونات ما وراء المعرفة يبدون أكثر الكيل تنظيما

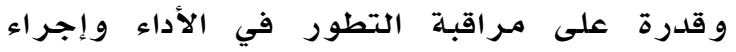

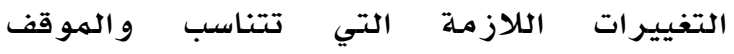
التعليهي. و ايضا قام بر اون (Brown, 1980) بتقديم نموذج

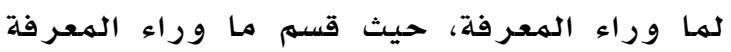

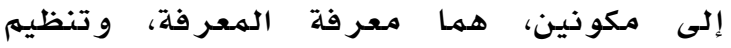

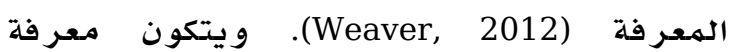

لقد ظهر مصطلح ما ور اء المعرفة في السبعينات من القرن الماضي مـن خلال البحوث التي قام بهاء

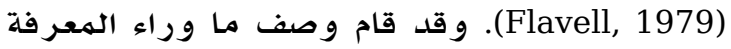

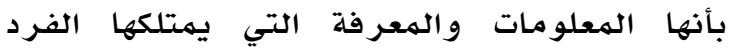
ويلدركها عن الظواهر والأحداث التي يمر بها. بها. و قام بتقسيه ما ور اء المعرفة إلى مكونين رئيسين

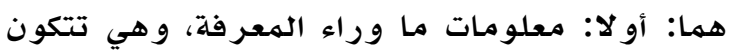
من معلومات حول المتغيرات أو الاستراتيجيات

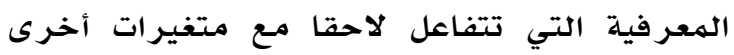
لتشكل الانجاز أو التحصيل. وكمثال على هذه هـه

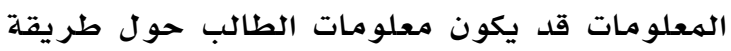
تعلهم مناسبة وسريعة لبعض المواقف التعليمية

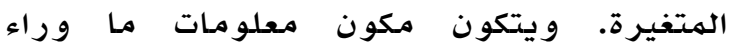

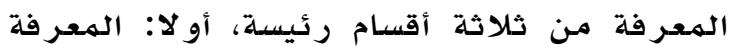

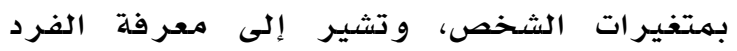

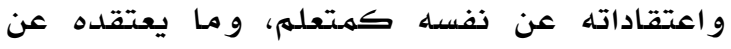
عمليات تفكير الآخرين. ثانيا: المعرفة بمتغير ات واتهات

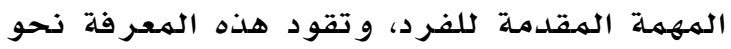

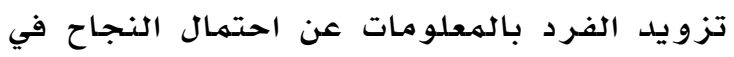

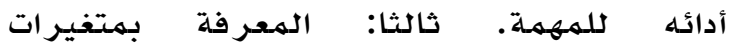

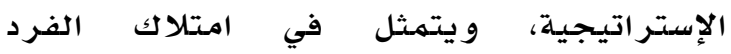

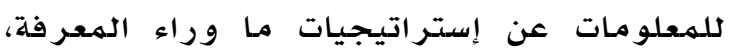
و التي يمكن من خلالها النجاح في تحقيق أهداف

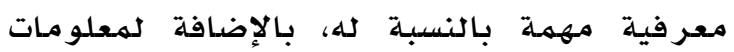
اخرى و التي تتعلق بالسؤال حول متى و أين

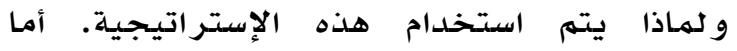
المكون الثاني فهو خبرات ما وراء المعر فة وتتمثل في الخطوات والتطور في الأداء في أثناء القيام

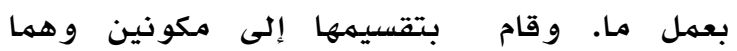

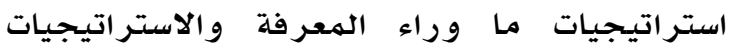
المعرفية. و ولعل الفرق بين المكونين قد يكون أكثر وضوحا عندما نقدم مثالا. فعندما يطلب من

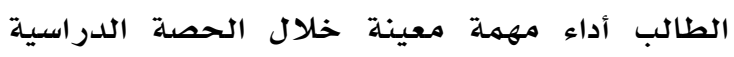
فأنه يقوم بالسؤال أولا فيما إذا كان استطاع فهم الهمانه السؤال أو الههمة بالشكل الهطلوب حتى يستطيع الهول الإجابة، وهذا يعكس إستر اتيجية ما وراء الهعر فلة. بينها تتمثل الإستر اتيجية الهعرفية في قيام الطالب 
من الإفر اد الذين تزيد أعمارهم عن بr سنـة مثثلا،

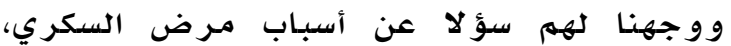

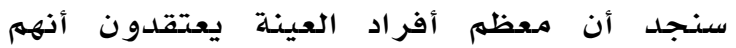

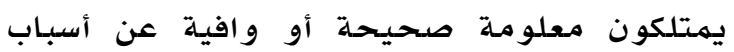
المرض، بينما هو غير ذلك.

و تشير العديد من الدراسات \&obias \& (إلى إن متتغير مـراقبـة Everson, 1996; 2009)

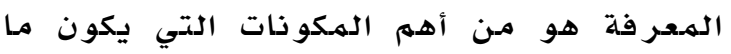
وراء الهعر فة وهذا يقوم على تفسير ملذخصة هو انه المسئول عن إصدار أحكام على المهادة

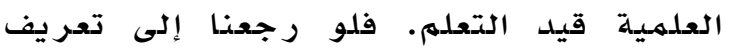
متغير مراقبـة الهمرفة لوجدنا أنه يفرق بين

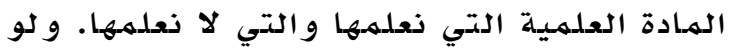
نظر نا بعين من التحليل لهما قد يقع بعد إصدار هذا الحكهم لوجدنا التالي، فعلى سبيل الهثال عندما يعتقد الطالب انه على معرفة فالقسمهة

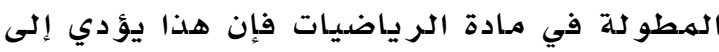
تقليص زمن الاستعداد لاختبـار مـادة الرياضيات الأمر الذي ينتج عنه انخفاض في التحصيل

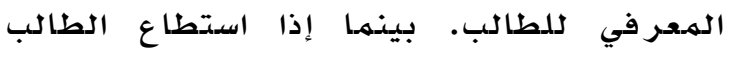
إدرالك انه لهم يصل إلى الفهم الجيد للقيد للقسهمة

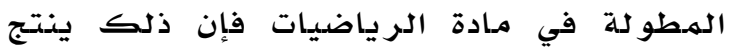
عنه توجيه و وتحكم في استراتيجيات التعلدم (مكون أخر من ضهمن ما وراء الهعر فية)، الأمـر

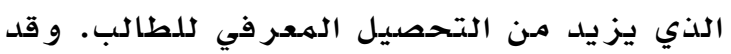

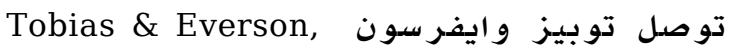

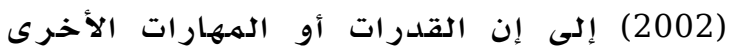

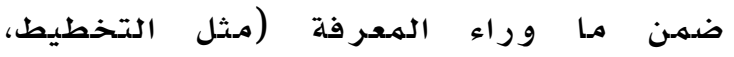

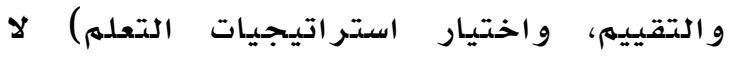
يمكن لها أن تعمل بالشكل الصديح إديار إذا كان

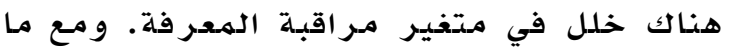

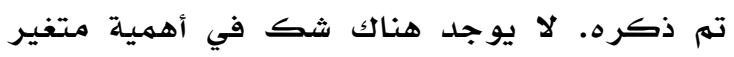

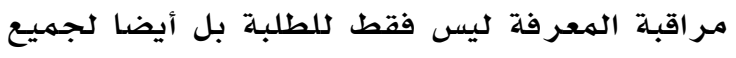

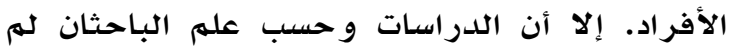

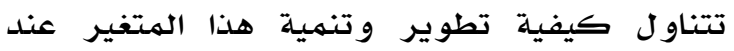
الطلبة. لذلك يفتر ض الباحثان ان طرق التدريس

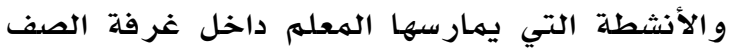
الدراسي لها تأثير في تطوير مهارة التفكير

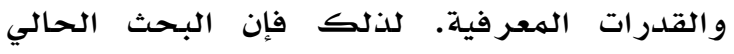
يبحث في أثر الأنشطة المتتمركزة حول تطوير
الهعر فة من المعر فة التصريحية، و المعر فة

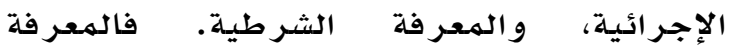

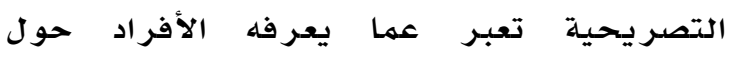

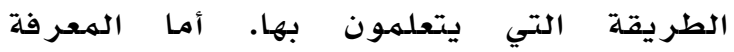

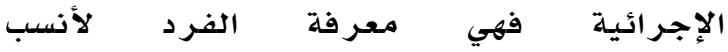

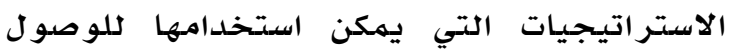
إلى أداء أفضل.وأما الهعرفة الشرطية فهي

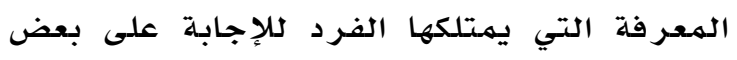

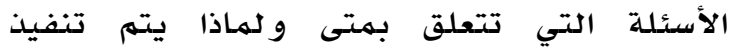

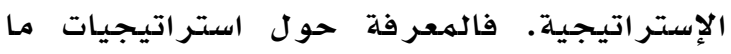

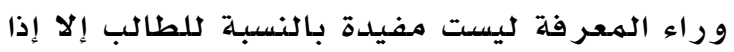

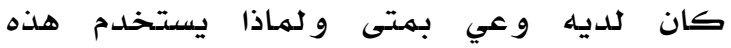

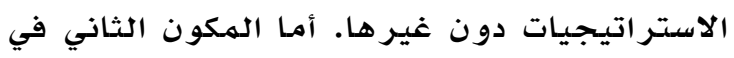
نهموذج براون فهو تنظيه الهعرفة، وهو يعبر عن

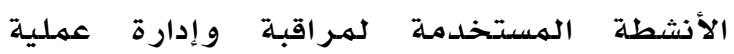
التعلهم، ويشمل التخطيط، والهمراقبة، و التقييهم.

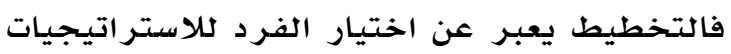

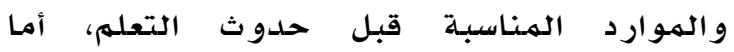

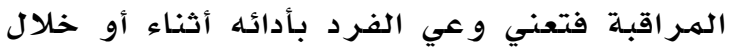

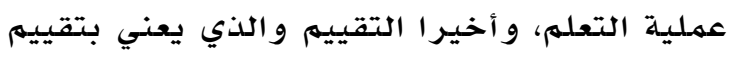

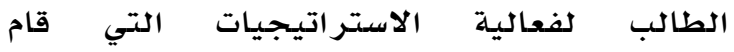
باستخدامها لتحقيق هدفه (Weaver, 2012). Tobias \& Everson, واتفق توبيز وايفر سدون

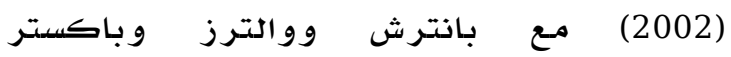

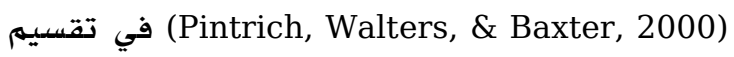

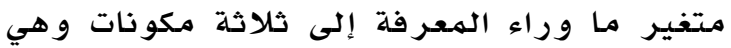

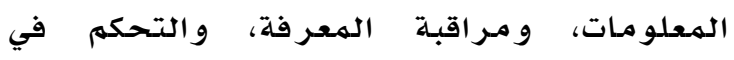

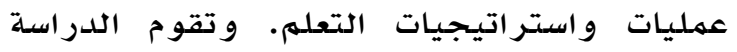

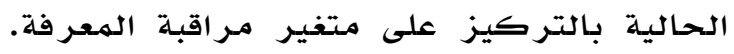
و التي يمكن تعريفه على أنه القدرة على مـر اقبـة

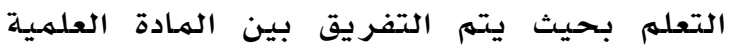
(الههمة قيد الانجاز ) التي تم تعلهها و فهما و بين

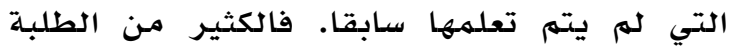

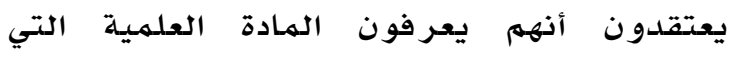

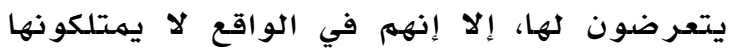
و لا يستطيعون حل الأسئلة المتعلقة بها. ليس الهول ذلك فحسب بل ووعلى مستوى الأنشطة اليومية التي نقوم بها، فالكثير منا يعتقد أنه يعلهم الكثير مـن المواضيع و في الحقيقة هو يفتقد الكثير من

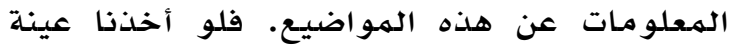


التفكير الناقد

يعد التفكير الناقد من أنواع التفكير التي لاقت اهتهماما من قبل التربويين مند فترة طويلة، و لكن الإهتتمام بـ زاد بشكل واضسح في السنوات

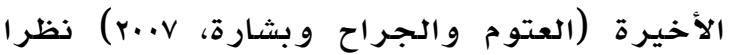
لانعكاساته العديدة على عملية التعلهم وقدرات اتل حل

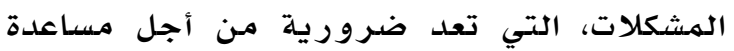
الطلبة على مواجهة تحديات الحياة المعاصرة.

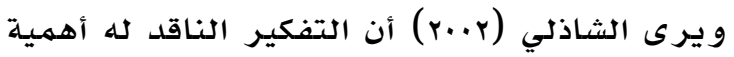
كبيرة في العملية التعليمية، فهو أحد مفاتيح

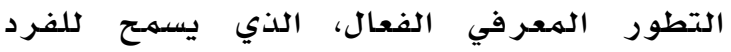
باستخدام أقصى طاقاته العقلية، من أجل التفاعل الايجابي مـع بيئته، و مواجهة ظروف الحياة التي

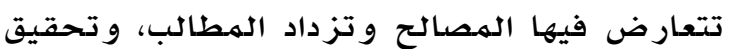
النجاح و التكيف مـع متطلبات هذه الحياة. لقد تعددت التعريفات التي أعطيت للتفكير الناقد بتعدد المدارس التربوية التي انطلق منها

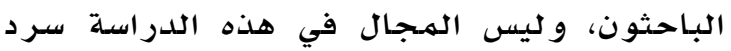

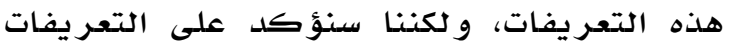
التي قد تكون أقرب إلى مدوضوع بحثنا الحالي و هو إدارة وتوجيه الهعر فة، كذلك الكي التعريفات الأحدث. فقد عرف فاسيون (Facione, 2011, 8) التفكير الناقد على أنه "حكم منظم ذاتيا، يهدف إلى التحليل، والتفسير، والتقييه، والاستنتاج،

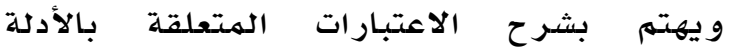
والبر اهين، والمفاهيم والطرق التي يستند إليها

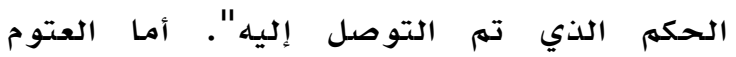

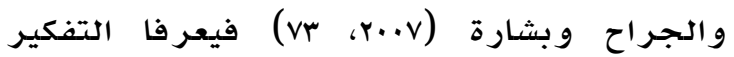

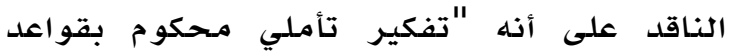
الهنطق و التحليل، يمارس فيه الفرد الافتر اضات لهات

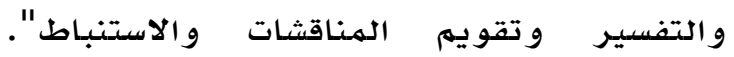

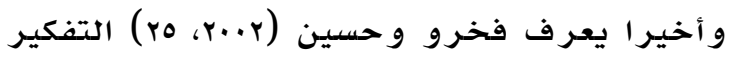

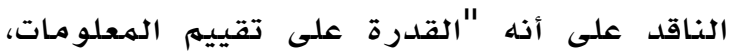
و فحص الآراء مـع الأخذ بعين الاعتبار وجهات

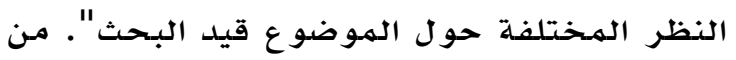

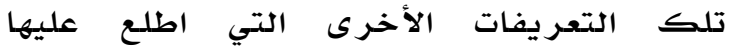

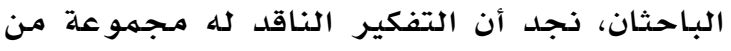

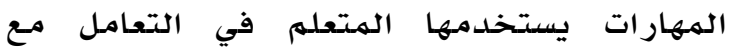
الظواهر و الأحداث من أجل فهم أفضل و أعمق
مهارات التفكير الناقد في تطوير مهارة الطلبة في مر اقبة المعر فلة. إن متغير مر اقبة الهعرفة يمكن الطالب من فالم

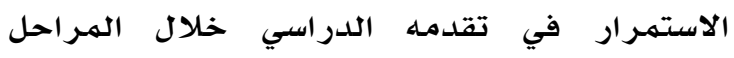
التعليمية، ولا يقتصر أهمية هذا المتغير على على الهال

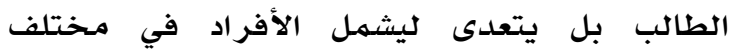

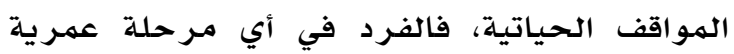
و في موقف يحتاج إلى إصدار حكم على المعلومـة

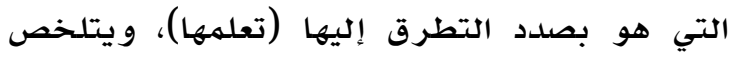

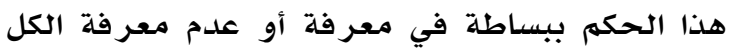

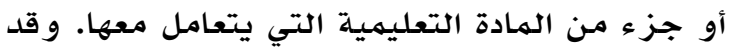
أثبتت الدر اسـات إلى أن هذا الحكمى (إذا كان دهان دقيقا) يساعد الطالب أو الفرد في اختصار الوقت والجهد التها

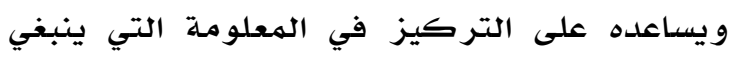
تعلمها، بينما إذا كان الحكم خاطئا أو لا يتميز الهيز بالدقة، فإن هذا لا يؤدي فقط إلى إهدار الوقت إدا و الجهل، وإنما أيضا ينتج عنه تحصيل دراسي منخفض (Al-Harthy \& Was, 2013).

و هناك العديد من الدراسات Heils \& Van) Kraayenoord, 2003; Yunus \& Ali, 2008)

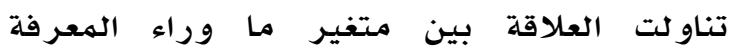
و الدافعية لتحصيل والانجاز. وتوصلت هذه

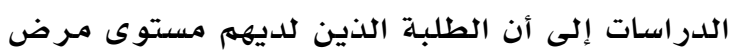

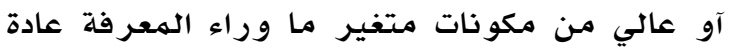

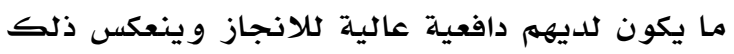

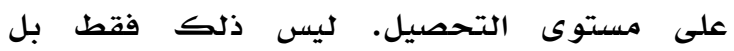
يستطيعون ترجمـة هذه الدافعية بشكل أكثر واقعي

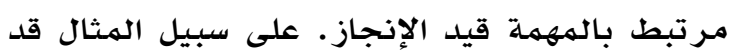

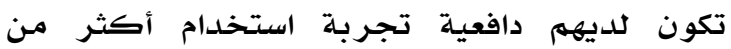

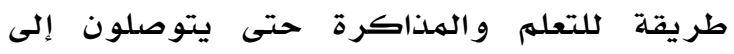
طريقة مناسبة تساعدهم على الفهم السريع وبالتالي استغلال الوقت والجهد. كذلك توصلت

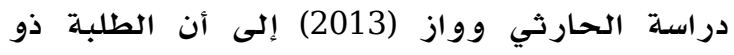

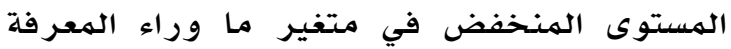

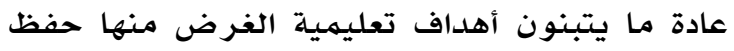
الذات وعدم التعرض على الإحراج الأمر الذي يؤدي إلى الرضي بالهستوى القليل من الانجاز والتحصيل المعرفي. 
و مهاراته في المواد الدراسة في صورة أنثطة وواجبات بيتية و تمارين كمية تتعامل مـع الأرقام، وهول و امتحانات مستمرة وغيرها من الطرق و والأساليب

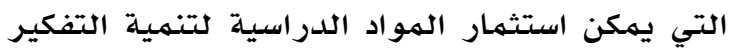
الناقد. أما بالنسبة للمشرفين فعليهم دعم المعلهم و تشجيع على تضمين التفكير الناقد في أثناء التخطيط لعملية التدريس وتنفيذها. أما المعله، فهو بلا شك يعد المحرك الأساسي في تنفيذ كل ما ورد أعلاه، فالتنفيذ الحقيقي لكل تلك الطرق

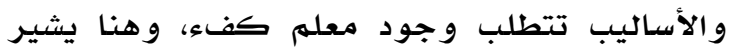

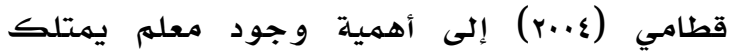
مهارات التفكير الناقد لكي يستطيع أن يدرب طلبته

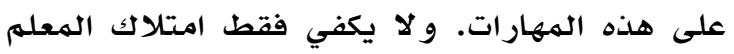
لمهارات التفكير الناقد، بل عليه أيضا البحث عن البه

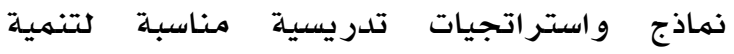

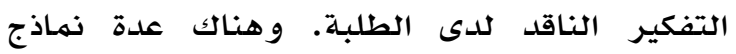

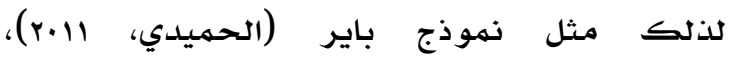
و النموذج المنظم من خلال الأسئلة لتعليم التفكير

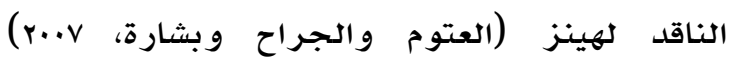
و نموذج روبرت فيشر في تنمية التفكير الناقد

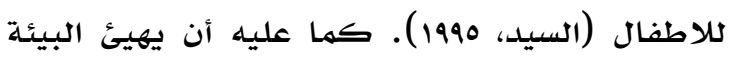

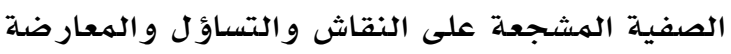

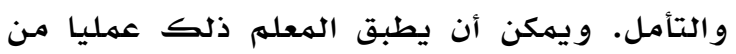
خلال تخصيص وقت أطول للمناقشات الصفية، و توفير مواد مقروءة تشجع الطلبة على التحليل

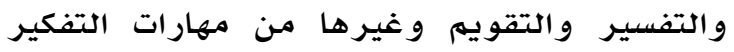

$$
\text { الناقد (عبيد و عفانة، r..r). }
$$

تعد مادة العلوم من المواد الغنية بالظواهر والأحداث الطبيعية والمشكلات البيئية التي يمكن ماده

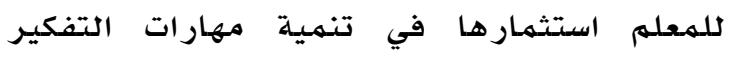
الناقد لدى طلبته. لكن كما ذكر نا سابقا أن هذا يتطلب معلم علوم ذا كفاءة وقدرة على تنفيذ أنشطة وتدريبات تساهم في ذلك. فهذه الأنشطة والتدريبات ينبغي أن تمحور حول الطالب، بحيث أنها تسهـح للطالب بهمناقشة الظواهر و المشكلات

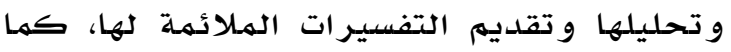
تشمل تدريب الطلبة على التساؤل والتأمل في

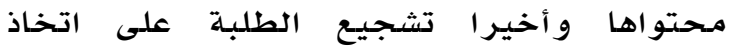

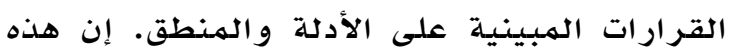

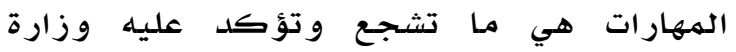

لتلك الظواهر و الأحداث، وبالتالي تبني قرارات و أحكام قائمسة على أسس موضو عية، و ليست على عوامل ذاتيلة تفقدها مصداقيتها، وهذه الهـارات تشمل التفسير و التقويهم والاستنباط والاستنتاج و التحليل و اتخاذ القرار، و تنظيهم الذات و التأمل. ولهئ. يعد التفكير الناقد أحد أنواع التفكير عالي

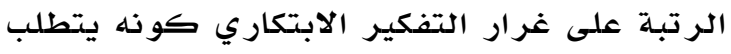

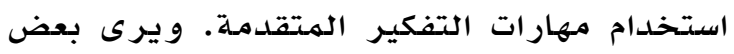

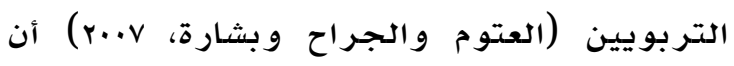

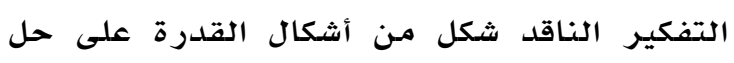

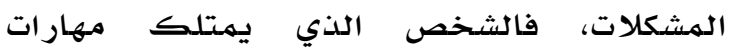
التفكير الناقد يستطيع التوصل إلى قرارات فعالة

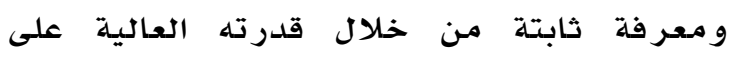
معالجة المعلو مات ومحاكمتها منطقيا و بفعالية

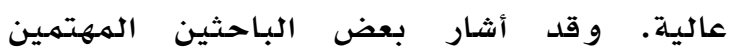

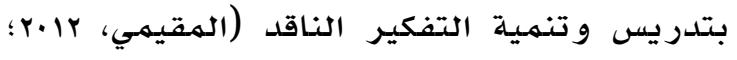

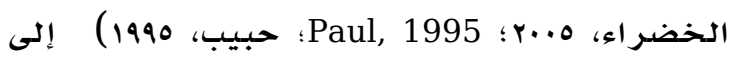

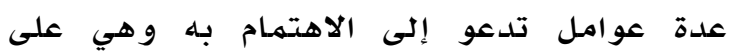

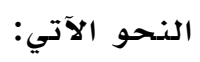

1. امتلاكك الطلبة لمهارات التفكير الناقد

يؤدي إلى فهم أعمق للهحتوى المعرفي.

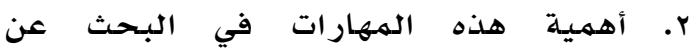

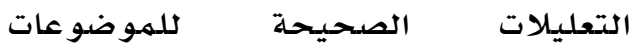

الصحيحة و البعد عن التعليلات الخاطئة. r. تشجيع روح التساؤل والبحث للتحقق من

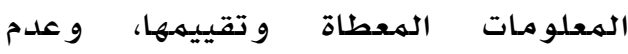
التسليم بها دون تحر كاف.

ع. مـراقبة الطلبة لتفكير هم وضبطه، لتكون افكارهم أكثر دقة وصحمة مـما يقودهم

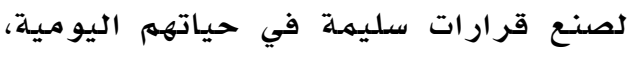
و البعد عن التطرف في الرأي، وتحررهيع

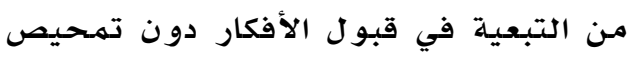

$$
\text { و تثبيت. }
$$

إن تعليهم الطلبة وتدريبهم على مهارات التفكير الناقد ليس بالأمر السهل، بل يحتاج إلى تكاتف

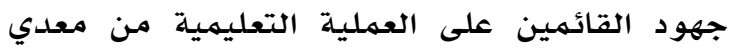
المناهج والهشرفين والهعلمين. فعلى معدي المناهج أن يعملوا على دمج التفير ولهير الناقد 
التفكير الناقد تؤثر في متغير مـراقبة الهعرفة. وهذه العلاقة بلدورها تؤثر على تحصيل الطلبة الطية الأكاديمي. و يمكن تلخيص مشكلة الدراسـة في السؤالين التاليين: هل تؤثر الأنشطة التدريبية

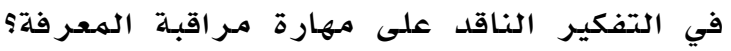
وهل توجد فروق دالة احصائيا في متغير مراقبة

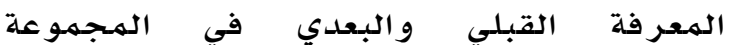

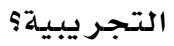

\section{أهمية الدراسة}

تكمن أهمية الدراسـة في أهمية الموضوع الذي

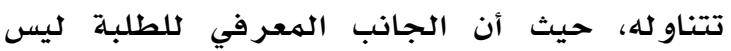
فقط مهما كلاستمـرار في المـراحل الدراسية، وإنما إنها أيضا تتعدى أهميته إلى أداء الكثير مـ الهـر الههام

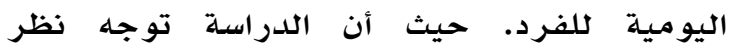
القائمين على مجال التعليه والتعلم بضرورة

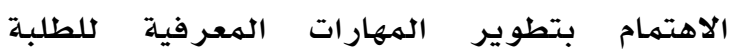
و كذلك الاهتهام باستراتيجيات التدريس والتي لها تأثير على إكساب الطلبة الههارات المعرفية. كذلك تبرز أهمية الدراسة في كونها تتعامل مـع الطلبة في المدارس الحكومية وتستخلدم أداة عملية لقياس متغير مـراقبة المعرفة بـلالا مـن استخدلـام أداة الاستبـانه والتي تعتمد على تقييم الفرد لنفسه. وتعتبر هذه الدراسة ذات أهمية في كونها من الدراسـات المحلية القليلة التي تبحث في المجال

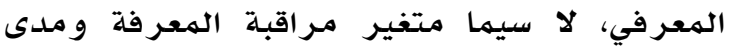
تطوره ونموه باستخدام أنشطة صفية في التفكير الناقد و علاقة ذلك بالتحصيل الدراسي للطلبة.

\section{مصطلحات الدراسة}

تضمنت الدراسة المصطلحات التالية:

ما وراء الهعرفة: المعلومات والمعرفة التي يمتلكها الفرد و ويدركها عن الظواهر والهاء والحداث التي يمر بها. وهي التي تمكنه من ادراة العمليات

المعر فية. - مئر

مر اقبة المعر فة: القدرة على مر اقبـة عملية التعلهم معرفيا بحيث يتهم يتتم اصدار حكما للتفريق بين

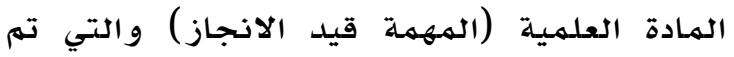
تعلهها وفهما وبين التي لهم يتهم تعلمها سـابقا.

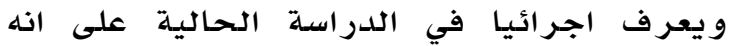

التربية و التعليه في سلطنة عمان، ذلك أن من ضمن أهداف تدريس العلوم بسلطنة عمان تنمية مهارات التفكير الناقد لدى الطلبـة المتمثثلة في

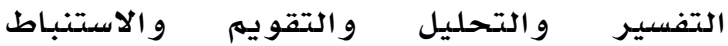
و الاستنتاج وفرض الفروض (وزارة التربية

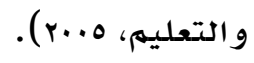

مشكلة الدراسة و أسئلتها

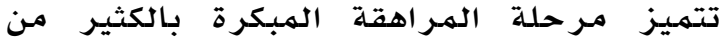

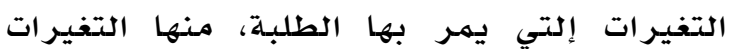

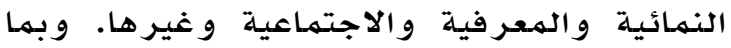

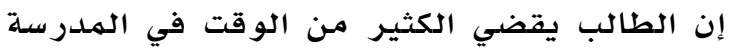
و التي بلدور ها تقدم العديد من الخبر ات التعليمية التي تساهم في حدوث هذه التغير ات وتطوير ها

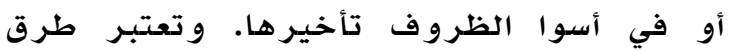
التدريس و التفكير التي يتعر ض لها الطالب من

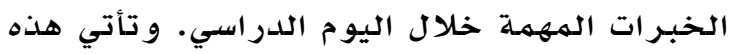

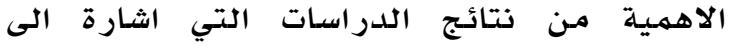
العلاقة الوطيدة بين طرق التدريس والتحصيل الدر اسي (Al-Harthy, Was, \& Isaacson, 2010) و ايضـا متغير مر اقبـة المعرفة و التحصيل الدر اسي

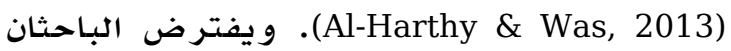

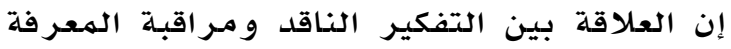
علاقة قوية ويجب بحثها. ويقوم هذا الافتراض على الشرح الذي تقدم ذكره. هذا بالإضدافة إلى أن التفكير الناقد عبارة عن طريقة تفكير تتميز

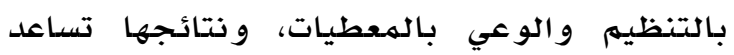
الطالب في اختيار الههارات الضرورية و أيضا

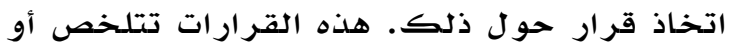
تظهر لاحقا في سلوكيات، كاستخدام طريقة الملخصات الصغيرة أثناء قراءة درس معين و عدم

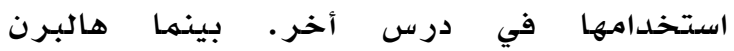
يؤكد على أن التفكير (Halpern, 1999)

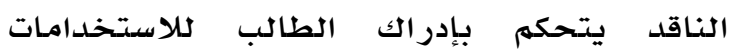

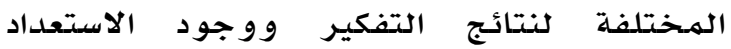
المعر في لتطبيق أفضلها. ويتضح مها تقدم شرحه إن هناك تقاربا في الههام المعرفية لكل مـن التفكير الناقد ومتغير مر اقبة المعرفة، الأمر الذي يعلل مشكلة الدئل الدراسلة بإفتراض الباحثان بأن الأنشطة التدريبية في 
تعلمها. وتكون اختبار المديرية من أسئلة

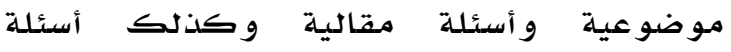
تركيبية تتطلب اجابة قصيرة. و قد تم الاعتماد على هذا الاختبار لقياس التحصيل لأنه أكثر ضبطا من ناحية الاعداد و يعد بهثابة معيار و اضتح في قياس التحصيل كونه أعد بطريقة تم مر اعاة

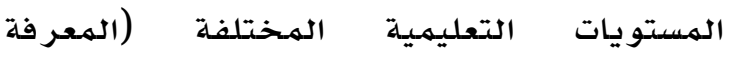

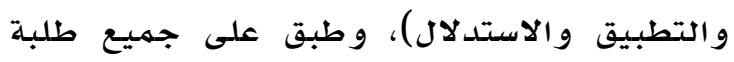

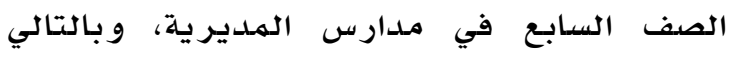

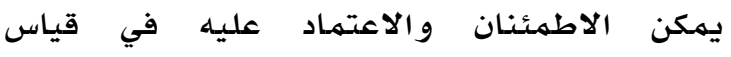
التحصيل الدراسي للطالبات في الوحدة.

طريقة التدريس باستخدام انشطة التفكير

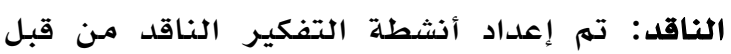

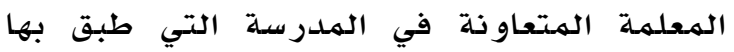

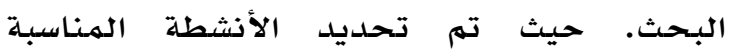
لمحتويات الوحدة التدريسية التي طبقت عليها

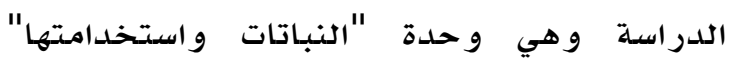

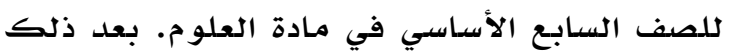
تم مر اجعة تلك الأنشطة من قبل مختصين من

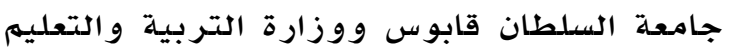

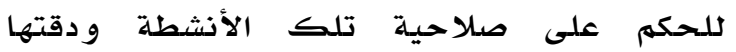

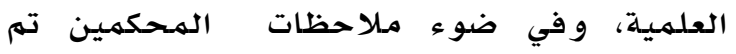
إخراج الأنشطة بصورة نهاية قابلة للتطبيق. اختبار مراقبة المعرفة: إن طريقة قياس مـراقبة المعرفة تتلخص في استخدام مهمة تعليمية، مثلا تعلم كلمـات جلديدة أو معادلات حسابية بحيث الميث يطلب من الهستجيب أو لا تحديد معرفته بالههمهة قيد الانجاز ومن ثم يطلب منه الاستجابة بالحل (Tobias \& Everson, 2000a) فقد تم بناء الاختبار بالتعاون بين الباحثين

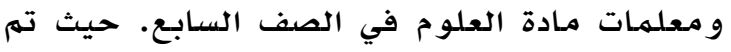

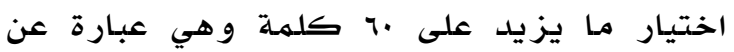
مصطلحات علميلة في مادة العلوم من المنهج المخصص لطلبة الصف السابع. و تمى استخدام صدق المحكمين للاداة حيث تم عرض الكلمات

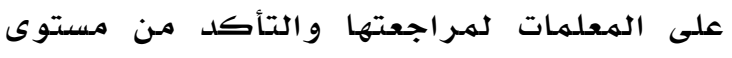

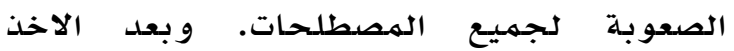
بملاحظات المحكمين، تكونت الصورة النهائية كلاختبار مـ ov مصطلحا، وتم تطبيق الاختبار في مـرحلتين: تتلخص الهـرحلة الأولى في عرض له
تحديد المستجيب اولا لهعرفته من عدمها لهصطلحات يتم عرضها عليه، وومن ثم يقوم باختيار التعريف الصحيح للمصطلح من بين عدة متغير ات.

التفكير الناقد: حكم معرفي من قبل المتعلدم و تميز هذا الحكم بالتنظيه، و يهاف إلى التحليل،

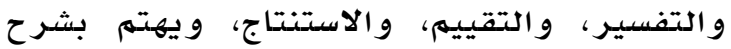
الاعتبارات المتعلقة بالأدلة و البر اهين، والهير، والهفاهيه و الطرق التي يستند إليها الحكم الذي تم التوصل إليـه.

\section{محددات الدر اسة}

يتحدد تعميم نتائج الدراسـة على مدى مماثلة

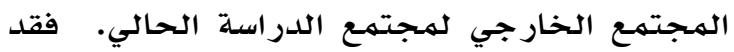
اقتصرت الدراسـة على الصف السابع في الحلقة الثانية من التعليم الاساسي. ووكذلك على منهج

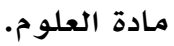

\section{الطريقة والإجر اءات}

\section{مجتمع الدراسة وعينتها}

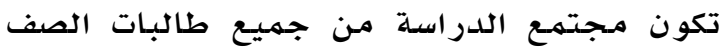

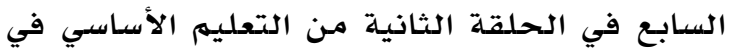
مدارس قطاع و ولاية السيب بحافظة مسقط،

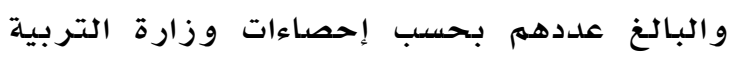

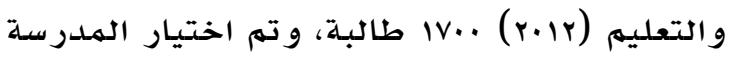
بعد ذلك بطريقة قصدية بسبب قربها من عمل إل

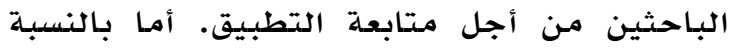

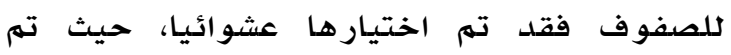
اختيار شعبتين من شعب الصف السابع، أحدهما

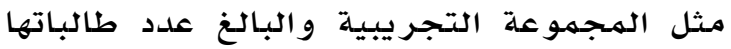

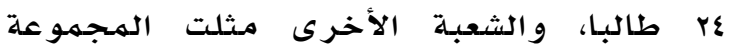
الضابطة وبلغ عدد طالباتها جا طالبة.

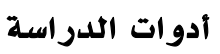
تمثلت أدوات الدراسة في الأتي:

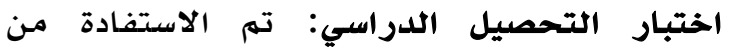

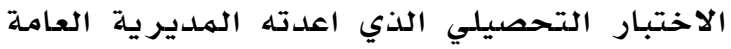
للتربية والتعليهم بمحافظة مسقط لهمادة العلوم

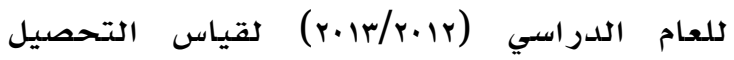
الدراسي للطالبات في الوحدة الدراسية التي تم 
العشو ائية (تجريبية وضابطة) بحيث تقوم معلمهة واحدة فقط بتدريس مادة العلوم للفصلين، وقدو تم التأكد من قدرة المعلمة على تطبيق الدراسلة

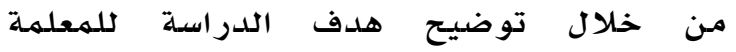
وكذلك مر اجعة أنشطة التفكير الناقد التي تم اعدادها من قبلها، وأخيرا متابعة الباحثين

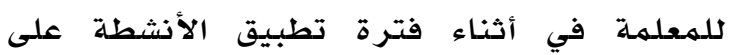

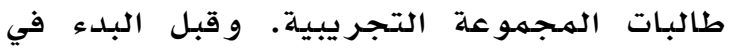
تطبيق تدريس مادة العلوم باستخدام التفكير الناقد تم تطبيق اختبار مراقبة الهعرفة (القبلي) على مـرحلتين. حيث تم عرض ov مصطلحا و قام

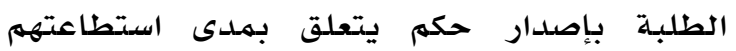
تعريف الهصطلحات. حيث يقوم الطالب بتحديد

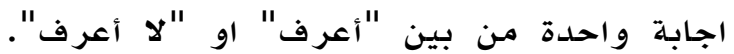
وبعد ذلك تبدأ المـرحلة الثانية من التهن التطبيق، حيث قام الطلبة بتعريف المصطلحات التي عرضت في المـرحلة الاولى وقام بإصدار حكمم عليها. وتهثلت الهـرحلة الثانية في انمان يقوم

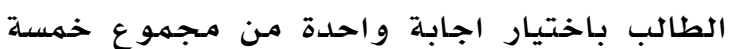
بدائل يعتقد انها التعريف الصحيح للهصطلح. وبعد الانتهاء من التطبيق القبلي لمتغير مراقبة

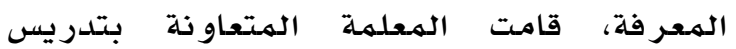

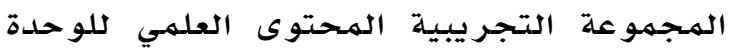

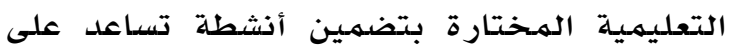
تنهية التفكير الناقد، وبتدريس المجمهوعة الضابطة نفس المادة العلمية و لكن بإستخدام الطريقة السائدة. ومن أجل معرفة أثر استخدام هذه الأنشطة في مراقبة المعرفة، تم في كل كل درس مـن دروس الوحدة تقديم نشاط أو نشاطين

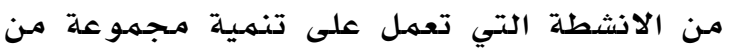

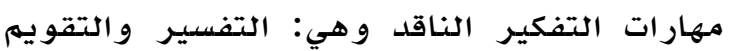

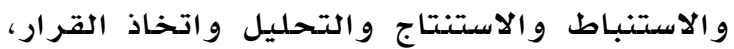

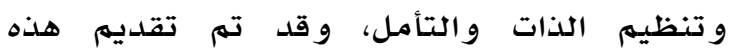

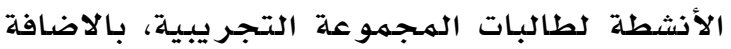
إلى ما هو مطلوب منهم من أنشطة الكتاب

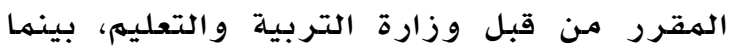

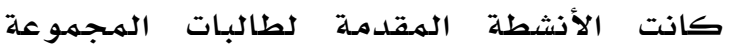

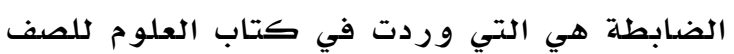

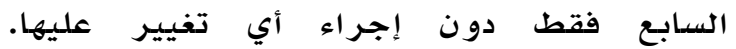

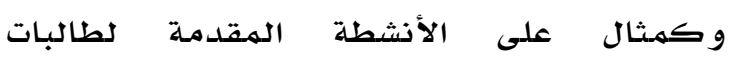

الهصطلحات جميعها على الطالبة ويطلب منها تحديد ما إذا كانت تستطيع تعريف المصطلح أو أو الو لا تستطيع ذلك. أما المرحلة الثانية فتبدأ فورا

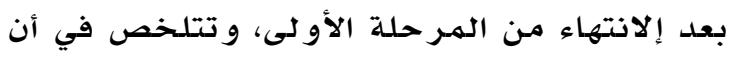

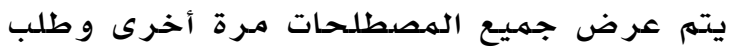

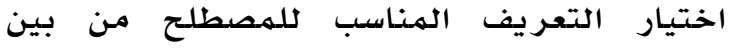
خمسدة بدائل. وجلدول ا يبين نظام الإجابة على احلى

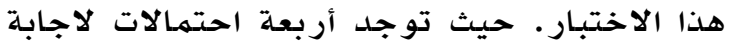

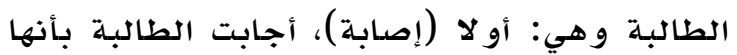

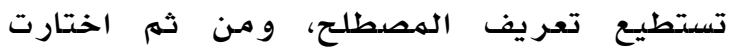

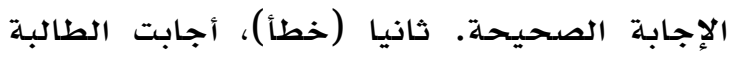

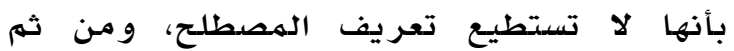

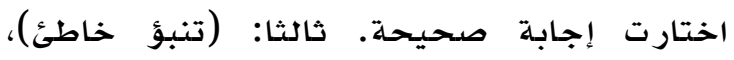

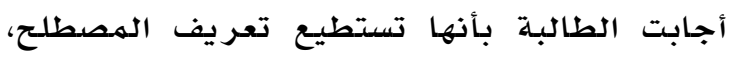

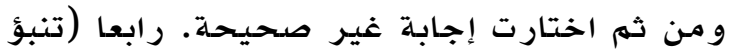

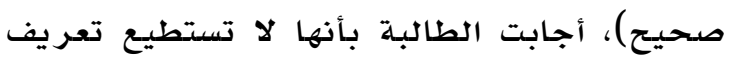
المصطلح، ومن ثم اختارت إجابة غير صحيحة صابة.

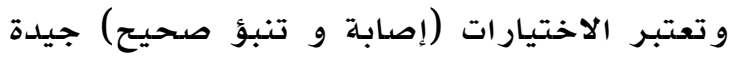

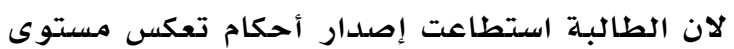
فهمها للمحتوى العلمي الذي ترغب في في تعلمهـ

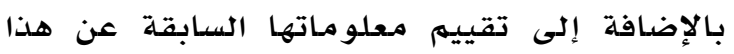

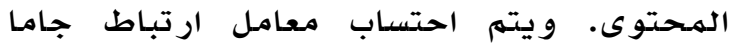
باستخدام الهمعادلة التالية:

(إصابة) (تنبؤ صحيح) - (خطاء) (تنبؤ خاطئ)

(إصابة) (تنبؤ صحيح) - (خطاء) (تنبؤ خاطئ) جاما $=(\gamma)$

\begin{tabular}{|c|c|c|}
\hline \multicolumn{2}{|r|}{ جلدول I } & الإجابات اله \\
\hline لا اعرف & اعرف & \\
\hline خطاء & إصابة & إجابة صحيحة \\
\hline تنبو صحيح & تنبؤ خاطئ & إجابة خاطئة \\
\hline
\end{tabular}

استخدمت الدراسـة الحالية المنهج شبـه التجريبي لملاءمتتة لطبيعة الأسئلة التي تهدف الدراسلة الإجابة عنها، فقد تم اختيار مدرسة لهـة بطريقة قصدية من مدارس قطاع و لاية السيب بهحافظة

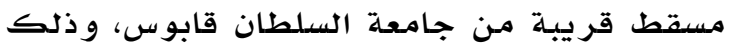
حتى يتمكن الباحثان مـن مراقبة و تطبيق البحثث، بعد ذلك تم اختيار فصلين دراسيين بالطريقة 
للكشف عن الدلالة الإحصدئية للفرق بين متوسطي الاختبار القبلي والبعدي لمتغي مر اقبـة

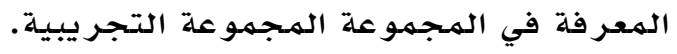

\section{نتائج الدراسة ومناقشتها}

هدفت الدراسـة الحالية إلى الإجابة على ثلاثة

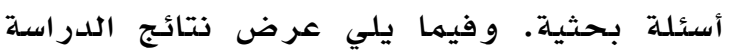

و مناقشتها:

إجابة السؤال الأول والذي ينص على: هل تؤثر

الأنشطة التدريبية في التفكير الناقد على مهارة

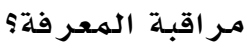
بداية تم احتساب المتوسط والاذحر اف المعياري لمتغير مراقبة المعرفة كما يوضع في جلدول

جدول ra

المتوسط والانحراف المعياري للارجات الاختبار القبلي والبعدي لمتغير

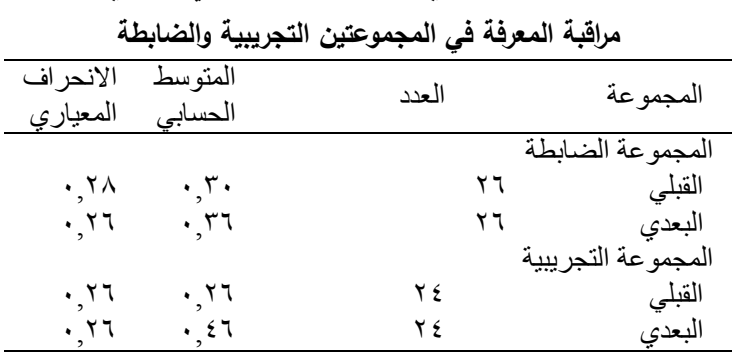

و للإجابة على هذا السؤال تم إجراء تحليل التباين المصاحب على الاختبار القبلي والبعدي البدي

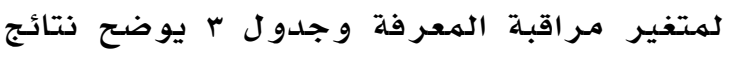

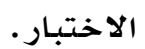

الهمجموعة التجريبية، في درس "التغيرات التي يحدثها الإنسـان في النظام البيئي"، تم تهيئة الصف كهمحكمة بحيث قسمت الطالبات إلى ثلاث

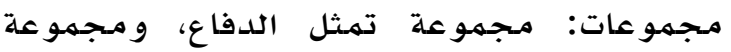

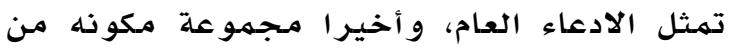

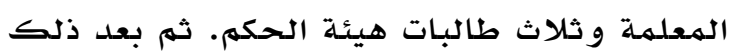
تم مناقشة دور الإنسان في البيئة هل هو ايجابي

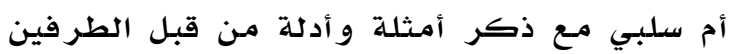

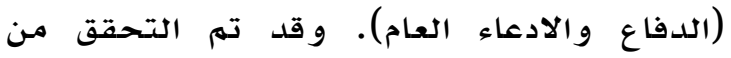

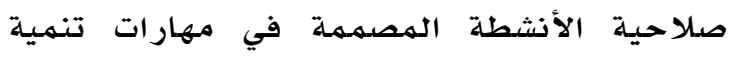

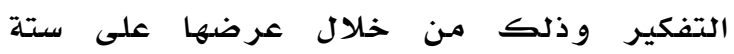

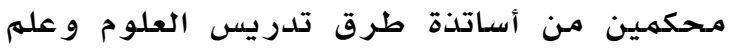
النفس التربوي ومشرفي مادة العلوم و معلميها. و في ضوء الملاحظات التي قدمت من قبل هؤلاء المحكمين تم إخراج الأنشطة بصورة نهائية قابلة للتطبيق. أما بالنسبة لتقديم الأنشطة في الحصدة الحس

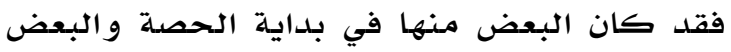

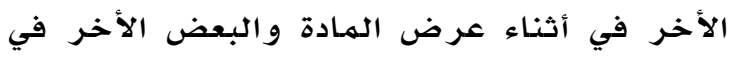

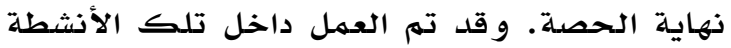
في معظمها على هيئة تعلم تعاوذي بين الطالبات، إذ يتهم النقاش بين أعضاء المـمهوعة الواحدة أو لا

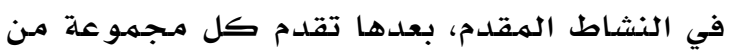
خلال المقرر مـا تم التوصل إليه على باقي أفراد

وبعد الانتهاء مـن تلدريس المحتوى العلهي

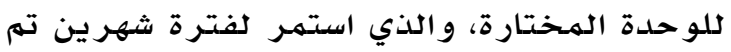

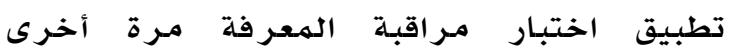
(البعدي). كذلك تم تحصيل درجات الطالبات في الاختبار التحصيلي في الوحدتين اللتين تم

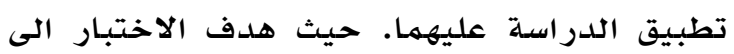
معرفة تحصيل الطلبـة العلمي في الوحدة. علما

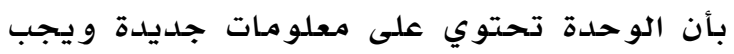
على الطالب تعلمهها وفهمها حتى يتقدم في مادة

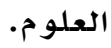

\section{المعالجة الإحصائية}

للإجابة على أسئلة الدراسـة، تم استخدم بر نامـج

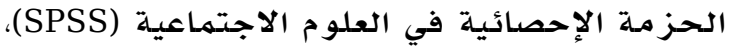

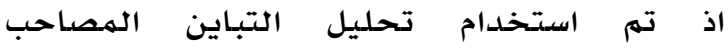
(ANCOVA) 
تحليل التباين المصاحب (ANCOVA) على الاختبار القبلي والبعدي لمتغير مراقبة المعرفة

\begin{tabular}{|c|c|c|c|c|c|}
\hline مستوى الدلالة & قيمة (ف) & منوسط المربعات & مجموع المربعات & د.ح & المجموعة \\
\hline$\cdot, 1$. & $\varepsilon, \cdot r$ & $\cdot, Y Y$ & $\cdot, r Y$ & 1 & القبلي \\
\hline \multirow[t]{2}{*}{$\cdot, \cdot r$} & $0, .9$ & $\cdot, \mathrm{r}$ & Tr, & 1 & البعدي \\
\hline & & $\cdot, .0$ & $\cdot, r V$ & $\varepsilon V$ & الخطأ \\
\hline
\end{tabular}

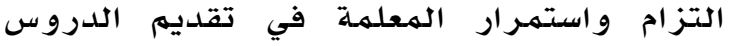

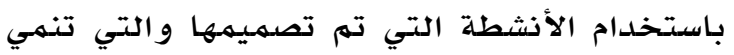
مهارات التفكير الناقد لدى الطالبـات. و لا يهكن

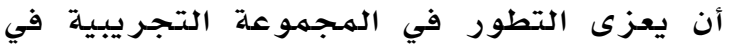

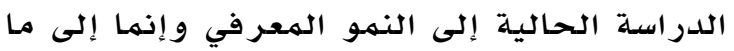
قدمته المعلمـة من أنشطة لتنمية مهارات التفكير

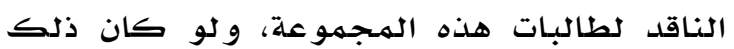
صحيحا، لكان هناك تطور أيضا في المجمموعة

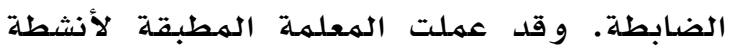
التفكير الناقد على توفير بيئة صفية مشجعة الماته على النقاش و التساؤل و المعارضية و التامل، فكما

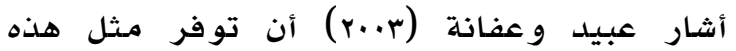

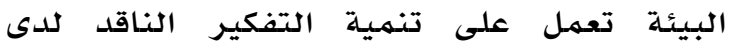

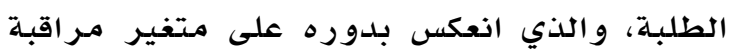
المعر فة لدى طالبـات المجهموعة التجر يبية. ودعما لذلك، فهـ خلال التطبيق لاحظت المعلمة الهطبقة لهذه الأنشطة، أن الطالبات

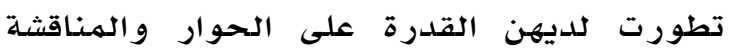
والإقناع لوجود أدلة وبراهين وأيضا أصبـحن

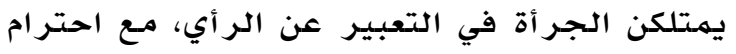

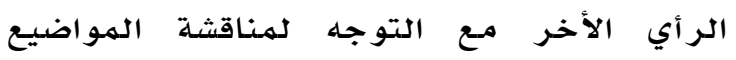

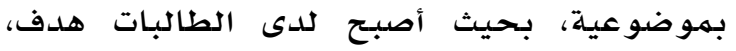

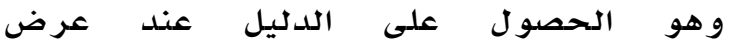
الموضوعات و القضايا المختلفة. وتظهر أهمر أهمية نتائج الدراسلة الحالية في التأكيد على أهمية

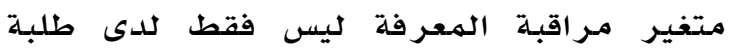
الهر احل التعليمية الهتوسطة و الجامعية، و إنما

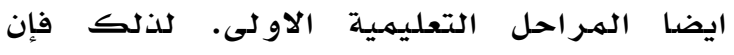

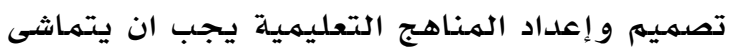
مـع تدريب وتمكين الطلبة من هذه الهـ المتغيرات

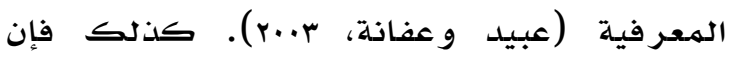
الدراسات الهستقبلية يمكن أن تبحث في مدى الدى الدي

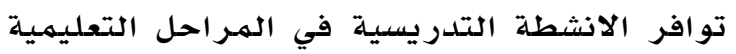

يتضح من جلدول r عدم وجود فرق دال إحصدائيا بين المجموعتين في الاختبار القبلي الامـر الذي

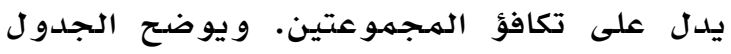

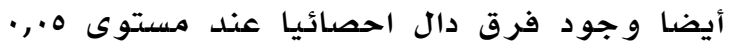

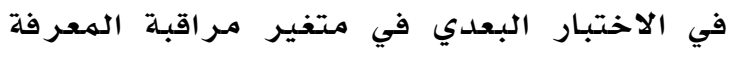

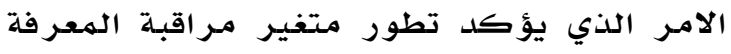

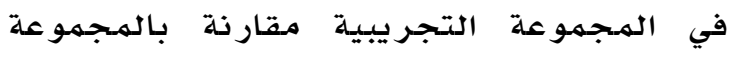
الضابطة. ويمكن تفسير هذه النتيجة إلى دور

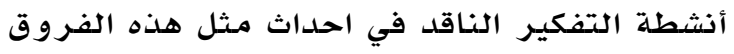

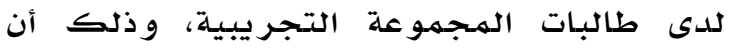
التفكير الناقد هو تفكير تأملي محكوم بقواعد

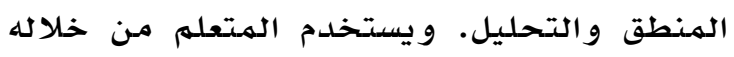
مهارة تقييه المعلومات وفحصها الأمر الذي

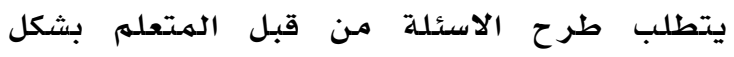
متواصل و ذلك حتى يستطيع أن يستمر في تعلهم المادة العلمية (Facione, 2011,8). إن طرح الأسئلة من قبل الطالبة خلال الحصدة

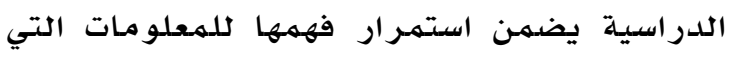
تم معالجتها، هذا و إن الطرق التي تم استخدامها

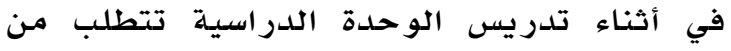
الطالبة القيام بدور ايجابي و عدم الاقتصار على القدئ تلقي المعلومة، فهي تتناقش مـع زميلاتها في الهات الهموضوعات الهـرورحة في تلك الأنشطة، و هذه مئه

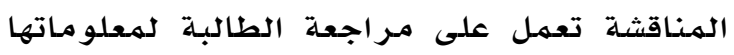
و تعديلها في ضوء ما تتلقاه من الأخرين، وهذا

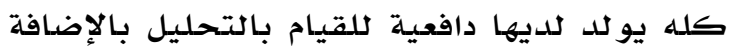

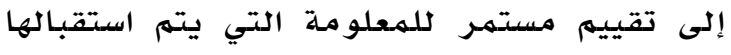

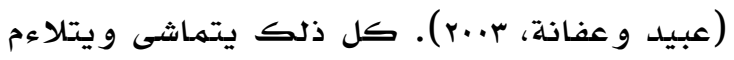
مـع متغير مراقبة المعرفة والذي يتطلب الحكم الهم على المعلومات التي يتم تعلمها فيما إذا كانت

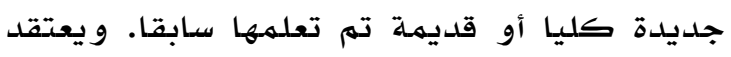
الباحثان أن التطور في مهارة مر اقبـة المعرفة فئة

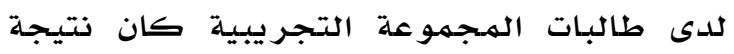


يمتلكون قدرة عالية في مهارة مـراقبة المعرفة، و بالتالي لا يتقدمون في تحصيلهم الدر اسي. وقد

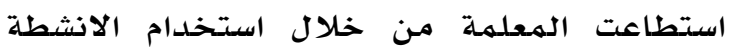

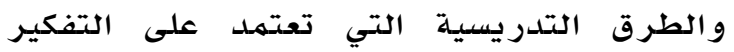
الناقد من حث الطالبات على اجراء أو القيام القيام بعملية التقييم والتصنيف للمعلومات قيد التعلهم. ثانيا: إن الطالبات الللاتي لديهن مهارة عالية في مـر اقبة المعرفة يحاولن بشكل مستهمر الحصول

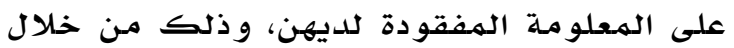

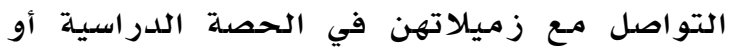

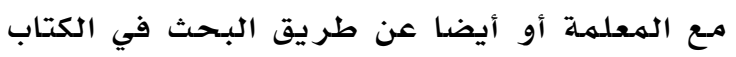

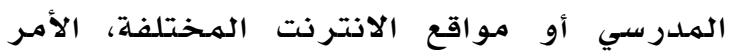

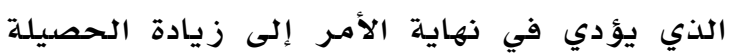

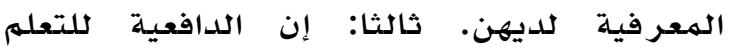

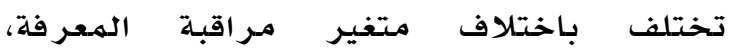
فالطالبات اللاتي لديهن دافعية عالية للتعلهم سرعان ما يفقدن هذه الدافعية إذا لهم يستطعن

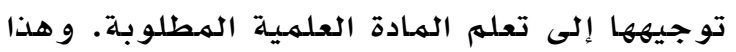

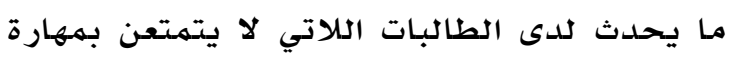

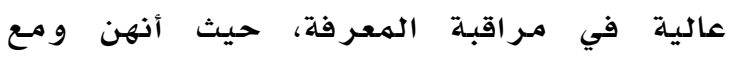
استهمرار الوقت يبدأن في وضع أهداف تعليمية بسيطة لا تتناسب و مستوى الدرس التعليمي الذي

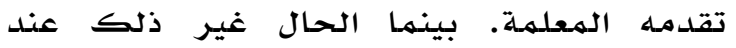

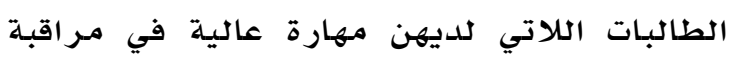
الهعرفة، فكلما استمرين في تعلم المـادة العلمية بشكل موجه و منظم كلهما قامن بتحقيق بعض الأهداف التعليمية ومن ثم الشعور بـالانجاز الذي مئي بدوره يضمن لديهن دافعية مستمهرة. وقد تتطور

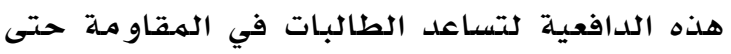

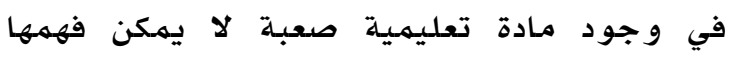

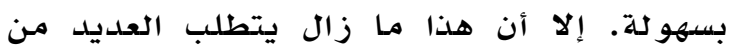

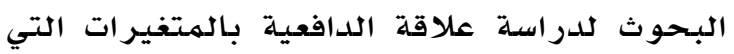
تناو لتها الدر اسـة الحالية.
الاولى والتي تساعد على تطور متغير مر اقبة

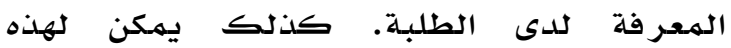

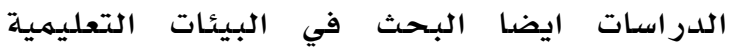

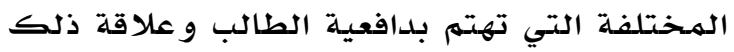
باستخدام الطلبـة للمهار ات المعرفية لهية.

إجابة السؤال الثاني والذي ينص على: هل توجد

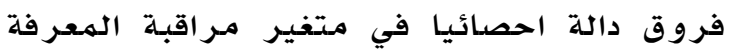

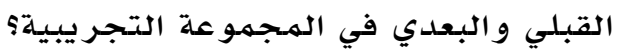

للاجابة عن هذا السؤال، تم احتسـاب اختبار (ت)

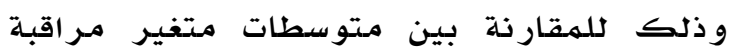

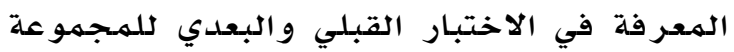

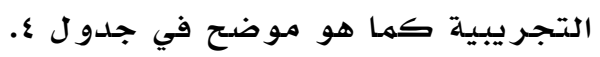
يتضح من جدول \& وجود فرق دال احصدائيا بين الاختبار القبلي و البعدي لمتغير مـر اقبـة المعرفة فئة

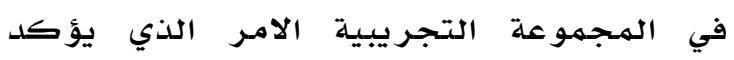

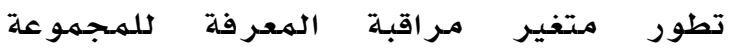
التجريبية ويعزى هذا التطور الى الطريقة التي فئي

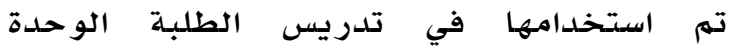
التعليهية. ويمكن تفسير نتيجة السؤالين الاول

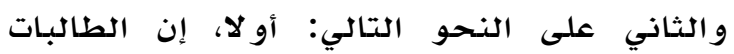

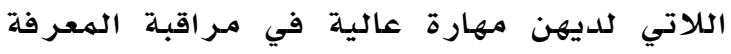
يستطيعن الحكم على المعلومات التي تقدمها لهن

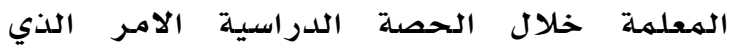
يمكنهن من تصنيف المعلومات إلى قسمين: قسهم

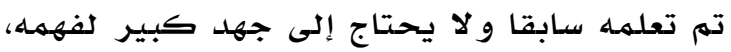

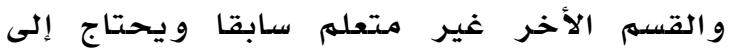

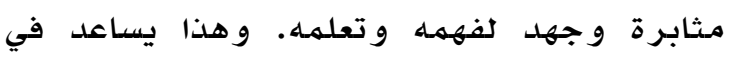

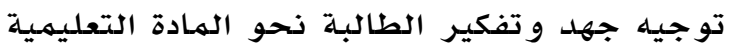

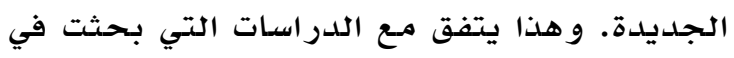
العلاقة بين متغير مراقبة المعرفة والتحصيل

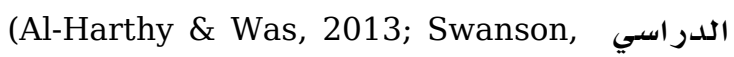
(1990. حيث أشارت نتائج هذه الدراسات إلى أن الن

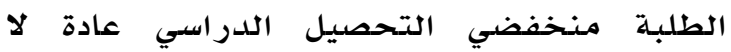
جدول ؛

\begin{tabular}{|c|c|c|c|c|c|c|}
\hline الدلالة & قيمة "ت" & د.د & $\varepsilon$ & 5 & ن & المجموعة \\
\hline & & 1 & • & • & $r \varepsilon$ & القبلي \\
\hline$\cdot, \cdot r$ & r,T. & $\varepsilon V$ & • & $\cdot, \leqslant 7$ & $r \varepsilon$ & البعدي \\
\hline
\end{tabular}


الحادي عشر. رسالة ماجستير غير منشورة، كلية التربية، جامعة السلطان قابوس.

السيد، عزيزة (1990). التفكير الناقد، دراسة في البي

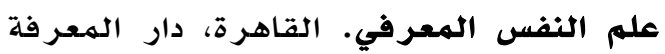

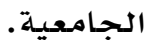

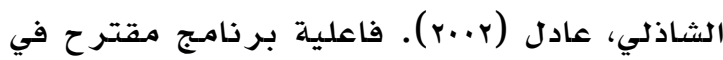

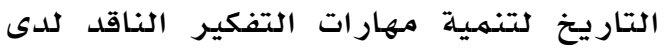

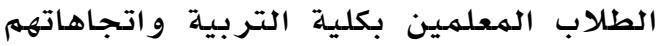

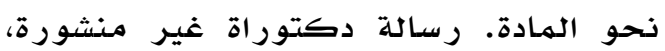
كلية التربية، جامعة الأزهر.

العتوم، عدنان، والجراح، عبدالناصر، وبشارة،

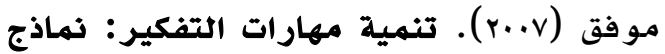
نظرية وتطبيقات عملية. عمان، دار المسيرة للنشر و التوزيع و الطباعة.

فخرو، عبدالناصر وحسين، ثائر (r..r). دليل مهارات التفكير، ..1 فكرة في التفكير.

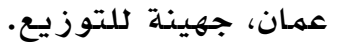

قطامي، نايفة (ع...r). مهارات التدريس الفعال. عمان، دار الفكر للنشر والتوزيع.

المقيهي، فاطمة (rا.r). أثر برنامج تدريبي مقترح في اكتساب معلمات الفيزياء مهارات التفكير الناقد و الممارسة الصفية لها. رسالة ماجستير غير منشورة، كلية التربية، جامعة السلطان قابوس.

وزارة التربية و التعليم (rا.r) المؤشرات التربوية، مسقط، وزارة التربية و التعليه.

وزارة التربية والتعليم (ب....). الوثيقة العامة للتقويم التربوي. مسقط، المديرية العامة لمتقويم التربوي.

وليم، عبيد، وعفانة، عزو (r.r.r). التفكير والمنهاج المدرسي. عمان، مكتبة الفلاح

$$
\text { للنشر والتوزيع. }
$$

Al- Harthy, I. \& Was, C. (2013). Knowledge monitoring, goal orientation, self-efficacy, and academic performance: a path analysis. Journal of College Teaching $\mathcal{E}$ Learning. 10 (4), 263- 277.
التوصيات والمقترحات

في ضوء النتائج التي توصلت إليها الدراسة الحالية، فإن الباحثين يوصيان بالآتي:

- ضرورة استخدام المعلمة لأنشطة تنمي التفكير الناقد في أثناء تدريس مادة العلوم لما لها من اثر فعال في تطوير

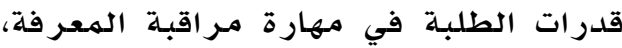
الأمر الذي ينعكس إيجابا على التحصيل

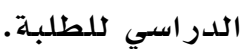
- ضرورة اهتمام معدي المناهج الدراسية لمادة العلوم وغيرها من المواد بتضمين المين أنشطة تعليمية صفية وغير صفية في التفكير الناقد تساعد الطلبة على تطوير

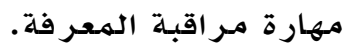
كما تقتر ح الدراسة:

- إجراء دراسة مماثلة وذلك لاختبار مهارات

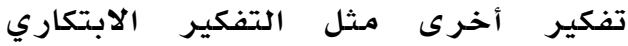
والتفكير الـتأملي، وذلك لدراسلة أثرها في تطوير القدرات المعرفية والتحصيل

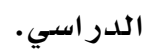

- إجراء دراسة مماثلة وذلك لاختبار أثر بعض طرائق التدريس مثل دورة التعلم وحل المشكلات، وذلك لدراسة أثرها في تطوير القدرات المعرفية والتحصيل

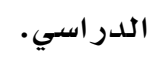

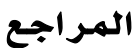

حبيب، مجدي (1990). دراسات في أساليب التفكير • القاهرة، مكتبة النهضة المصرية. الخضراء، فادية (م...r). تعليم التفكير الابتكاري

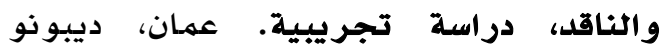
للطباعة و النشر و التوزيع.

الحميدي، شمسة (r.11). أثر استخدام إستراتجية باير للتدريس المباشر لمهارات التفكير في تنمية مهارات حل المشكلات التهات التهرات والتحصيل في الفيزياء لدى طالبات الصف 
Al-Harthy, I. Was, C., \& Isaacson, R. (2010). Goals, efficacy and metacognitive selfregulation: a path analysis. International Journal of Education, 2, 1-20.

Bandura, A. (1977). Self-efficacy: Toward a unifying theory of behavioral change. Psychological Review, 84, 191-215.

Brown, A. L. (1980). Metacognitive development and reading. In R. J. Spiro, B. B. Bruce, \& W. F. Brewer (Eds.), Theoretical issues in reading comprehension (pp.453481). Hillsdale, NJ: Erlbaum Associates.

Cross, D. R., \& Paris, S. C. (1988). Developmental and instrumental analysis of Children's metacognition and reading comprehension. Journal of Educational Psychology, 80, 131-142.

Facione, P. (2011). Critical thinking: what it is and why it counts. Retrieved from World Wide Web 21, April, 2014: http/ / www. insightassessment.com

Flavell, J. H. (1979). Metacognition and cognitive monitoring: a new area of cognitive developmental inquiry. American Psychologist, 34, 906-911.

Halpern, D. F. (1999). Teaching for critical thinking: helping college students develop the skills and dispositions of a critical thinker. New Directions for Teaching and Learning, 89, 69-74

Paul, R. (1995). Critical Thinking: How to Prepare Students for a Rapidly Changing World. Santa Rosa, Foundation for Critical Thinking

Pintrich, P. R., Walters, C., \& Baxter, G. (2000). Assessing metacognition and selfregulated learning. In G. Schraw \& J. Impara (Eds.), Issues in the Measurement of Metacognition (pp. 43-97). Lincoln, NE: Buros Institute of Mental Measurements.

Schraw, G., \& Dennison, R. (1994). Assessing metacognitive awareness. Contemporary Educational Psychology, 19, 460-475.

Swanson, H. L. (1990). Influence of metacognitive knowledge and aptitude onproblem solving. Journal of Educational Psychology, 82(2), 306-314.
Tobias, S., \& Everson, H. T. (2000a). Cognition and metacognition. Educational Issues, 6, 167-173.

Tobias, S., \& Everson, H. T. (2002). Knowing what you know and what you don't: Further research on metacognitive knowledge monitoring (College Board Report. No. 2002-03). New York: College Board.

Tobias, S., \& Everson, H. T. (2009). The importance of knowing what you know: A knowledge monitoring framework for studying metacognition in education. In

D. J. Hacker, J. Dunlosky, \& A. C. Graesser (Eds.), Handbook of Metacognition in Education (pp. 107-127). New York, NY: Routledge. 